\title{
RELIGIÕES E ELEIÇÕES EM PORTO ALEGRE: UM COMPARATIVO ENTRE 2000 E 2004
}

Ari Pedro Oro ${ }^{1}$

Resumo: Este texto efetua uma análise comparativa acerca das relações entre religião e política tais como ocorreram nas eleições municipais de 2000 e de 2004 em Porto Alegre, tanto para as eleiçōes majoritárias quanto para as proporcionais. Ver-se-á que tal relação se dá por iniciativas provenientes tanto do campo político quanto do religioso e que, nas últimas eleições, a própria diversidade religiosa porto-alegrense se fez presente no pleito municipal, através de candidatos que representavam tal pluralismo. No entanto, a vitória foi obtida somente por representantes dos segmentos católico, judaico e evangélico (Universal do Reino de Deus e Adventista do Sétimo Dia). Algumas hipóteses serão avançadas acerca do êxito destas expressões religiosas e do fracasso das demais: espírita, afro-brasileira, "Nova Era", evangélicas históricas e pentecostais.

Palavras-chave: pentecostalismo, política, diversidade religiosa, eleições 2004 em Porto Alegre.

Keywords: pentecostalism, politics, religious diversity, elections 2004 in Porto Alegre.

Mais uma vez em Porto Alegre, mas não somente aqui, comprovamos o acerto das afirmações de dois importantes analistas da relação entre religião e política no Brasil. São eles, Joanildo Burity, que afirma: "Os partidos e candidatos que não levam em consideração os grupos religiosos em seu discurso e estratégia correm sério risco de se complicarem ou inviabilizarem eleitoralmente" (Burity, 1997, p. 46); e Pierre Sanchis, para quem "as formas contemporâneas de religião não vão mais deixar de articular-se visivelmente à política...” (Sanchis, 2001, p. 40).

${ }^{1}$ Professor do Departamento de Antropologia e do Programa de Pós-Graduação em Antropologia Social da UFRGS e pesquisador do CNPq.

Debates do NER, Porto Alegre, ano 5, N. 6, P. 9-34, Dezembro 2004 
De fato, ambos os movimentos ocorreram nas eleições municipais de 2004 em Porto Alegre, ou seja, como veremos neste texto, tanto os partidos políticos, embora em grau diferenciado entre eles, assim como os candidatos ao executivo e ao legislativo municipais, não se furtaram de recorrer às igrejas e religiōes para conquistarem seu apoio, isto é, os votos dos seus fiéis e seguidores, quanto as próprias igrejas e religiōes não deixaram de se fazer presentes no campo político, mobilizando-se na perspectiva de eleger os seus representantes.

Procuraremosexplicitar esses aspectosao longo deste texto que tem, também, como objetivo, proceder a uma análise comparativa entre as eleiçôes de 2000 e de 2004, na capital gaúcha, relativamente às relações entre religião e política. Iniciemos, pois, por recordar o que ocorreu no ano de $2000{ }^{2}$

\section{POLÍTICA E RELIGIÃO NAS ELEIÇÕES 2000 EM PORTO ALEGRE}

Naquelas eleições, na campanha para o executivo municipal, a coalizão União Trabalhista (formada por 4 partidos: PDT, PTB, PTN e PMN), tinha como candidatos dois políticos conhecidos pelos seus vínculos religiosos, a saber: Alceu Collares, candidato a prefeito, afro-descendente e simpatizante para uns, membro para outros, das religiōes afro-brasileiras, e Son ia Santos, candidata a vice-prefeita, eva ngélica, sem vínculo denominacional estrito. Por ocasião da campanha, ambos os políticos não acionaram em público, diretamente, a sua pertença religiosa, embora contassem com um não dito, mas amplamente sabido, dos seus pertencimentos religiosos. Esta coalizão obteve $20,7 \%$ dos votos, concorrendo com a Frente Popular no segundo turno, tendo sido derrotada.

Por sua vez, a Frente Popular - cujos candidatos eram Tarso Genro

\footnotetext{
${ }^{2}$ Procedo aqui a um rápido resumo de um texto que escrevi em 2001 e que contou com reaçôes de vários colegas, tudo isto tendo sido reunido no N. 3, do Debates do NER, que veio a público em 2001.
}

Debates do NER, Porto Alegre, ano 5, N. 6, P. 9-34, DeZembro 2004 
para prefeito e João Verle para vice-prefeito - obteve durante a campanha eleitoral apoios religiosos explícitos de líderes de diferentes religiōes. Assim, o então Bispo Carlos Rodrigues (deputado federal e principal articulador político da Igreja Universal do Reino de Deus), ${ }^{3}$ o pastor Hermílio Lima (Vice-Presidente da Assembléia de Deus Madureira - RS), o irmão católico Antônio Cecchin (conhecido em Porto Alegre pelos seus longos anos de atuação junto às camadas de baixa renda da periferia da cidade), o reverendo Maurício de Andrade (da Igreja Anglicana do Brasil), o pastor Paulo Lima (da Igreja Batista Nova Vida), o pai-de-santo Adalberto Pernambuco Nogueira (então presidente do Conselho Superior dos Cultos Afro-Brasileiros), ${ }^{4}$ todos compareceram no espaço eleitoral gratuito no rádio e na televisão para explicitar seu apoio pessoal à chapa da Frente Popular e para convocar os membros de suas igrejas e religiōes a fazerem o mesmo.

Nas mesmas eleições, 18 candidatos explicitaram seus vínculos religiosos, sobre um universo de 411 que disputaram as 33 cadeiras na Câmara Municipal. O predomíniofoi de candidatosevangélicos, a saber: 4 da Assembléia de Deus, 3 da Igreja Universal, 1 da Igreja Quadrangular, 1 da Igreja Batista Filadélfia e 1 da Igreja Adventista, totalizando 11 candidatos. Deles, somente 2 foram eleitos, ambos da Universal, indicados e apoiados plenamente pela igreja. São eles os pastores Valdir Caetano, do PTB, que obteve

\footnotetext{
${ }^{3}$ A partir de 1996 Carlos Rodrigues se desincumbiu como o principal coordenador político da Igreja da Igreja Universal. No entanto, no final de fevereiro de 2004, Bispo Rodrigues foi afastado de suas funçôes de bispo e de coordenador político da igreja, por determinação do Conselho de Bispos da Igreja. O motivo do afastamento, segundo notícias veiculadas na imprensa, foi o envolvimento do mencionado bispo com Waldomiro Diniz, ex sub-chefe de Assuntos Parlamentares do Planalto. Segundo o jornal Folha de São Paulo, a decisão de afastar BispoRodrigues do Conselho de Bispos e da liderança da bancada da igreja na Câmara foi tomada por Edir Macedo para preservar a Universal e a candidatura do senador Marcelo Crivella (PL) à prefeitura do Rio. Ainda segundo o jornal, o fundador da Universal entendeu que teria havido "desvio de conduta" por parte de Rodrigues quando este nomeou diretores da Loterj durante a gestão de Waldomiro Diniz (Folha de São Paulo, 20/02/2004).

${ }^{4}$ Este importante líder religioso faleceu em Porto Alegre, em 23/9/2004, aos 76 anos de idade.
} 
10.913 votos, e Almerindo Filho, do PFL, que obteve 7.645 votos. Juntos somaram 18.744 votos, contra 8.842 votos obtidos pelos 4 membros da Assembléia de Deus (1 pastor, 2 membros e 1 evangelista), 2.333 votos alcançados pelo pastor da Igreja Quadrangular, 1.949 votos obtidos pelo membro da Igreja Batista Filadélfia e 344 votos pelo membro da Igreja Adventista.

Pelo campo católico, concor reram à vereança 1 sacerdo te, Padre Claudiomir Ceron - coordenador da Casa Aberta para crianças do Morro da Cruz, na capital - pelo PDT, não eleito, e 1 leigo, engajado nas atividades de várias paróquias da capital, João Carlos Nedel, pelo PPB, eleito com 6.039 votos. Além deles, porém, concorreram e se elegeram quatro outros candidatos que embora não tenham explicitado publicamente o seu vínculo católico durante a campanha eleitoral, formam, juntamente com o vereador Nedel, o que se pode chamar de "bancada católica" na Câmara Municipal. São eles, Beto Moesch, do PPB, que obteve 6.295 votos, Ervino Besson, do PDT, com 4.179 votos, Carlos Alberto Garcia, do PSB, com 5.580 votos, e Aldacir Oliboni, do PT, com 5.188 votos.

O Judaísmo, embora não diretamente, tem um seu representante na câmara municipal, que foi re-eleito para segunda legislatura, pelo PDT, com 10.830 votos, o judeu Isaac Ainhorn. Embora sua propaganda política não invista diretamente sobre este segmento étnico e religioso, colheu dele parte significativa dos seus votos.

Enfim, as religiōes afro-brasileiras contaram com 5 candidatos, 4 paisde-santo, que assim se identificaram publicamente, e 1 líder de terreiro, referência não explicitada abertamente. Nenhum deles foi eleito e juntos totalizaram 5.643 votos.

Nas eleiçôes 2000, notou-se que a Igreja Universal amealhou quase 19.000 votos, mais da metade do que todas as demais denominações evan-

\footnotetext{
${ }^{5}$ Diga-se de passagem que ambos os vereadores, logo no início do seu mandato, trocaram de partido, o primeiro filiando-se ao PL e o segundo ao PSL. Vale esclarecer, ainda, relativamente ao terceiro candidato da Universal, Veranice Neto, que se trata de um membro da igreja que ingressou na política por conta própria, não recebendo nenhum apoio de parte da Igreja. Obteve, então, 186 votos.
}

Debates do NER, Porto Alegre, ano 5, N. 6, P. 9-34, DeZembro 2004 
gélicas juntas; que os 5 representantes das religiōes afro-brasileiras não conseguiram, juntos, votos suficientes para eleger 1 vereador na Câmara Municipal de Porto Alegre; e que os 4 representantes da igreja Assembléia de Deus dividiram entre si parcela importante dos votos provenientes desse meio religioso, cuja conseqüência foi a não-eleição de nenhum deles.

\section{POLÍTICA E RELIGIÃO NAS ELEIÇŌES 2004}

De forma semelhante às eleições ocorridas em 2000, também nas eleições de 2004 verificamos a aproximação entre religião e política, por iniciativas provenientes de ambos os campos. Igualmente, tal aproximação ocorreu tanto nas eleições para o executivo quanto para o legislativo municipal.

\section{A RELIGião na CAMPanha Para o EXecutivo Municipal}

Entre as nove chapas que concorreramà prefeiturade PortoAlegre, duas apresentaram candidatos que detém reconhecido vínculo religioso. São elas, as chapas da coligação PFL-PSDB e da coligação PPS-PTB. A primeira tinha como candidato a prefeito o deputado federal pelo PFL Onyx Lorenzoni, que proclama publicamenteo seu vínculo com o luteranismo,membro que é da Igreja Evangélica de Confissão Luterana do Brasil, sendo consideradopelo Jornal Zero Hora como um "luterano praticante" (Zero Hora, 16/8/2004). A segunda chapa, liderada pelo candidato vencedor das eleições municipais de Porto Alegre, José Fogaça, possuía como candidato a vice-prefeito outro evangélico. Trata-se do deputado estadual Eliseu Santos. ${ }^{6} \mathrm{Em}$ ambos os casos, a identidade religiosadesses candidatosfoi pouco acionadapublicamente em-

${ }^{6}$ Eliseu Santos foi eleito em 2002 para o seu terceiro mandato a deputado estadual. Nasceu numa família da Assembléia de Deus. É formado em medicina, com especialização em cirurgia ortopédica. Nunca abandonou essa sua profissão apesar da atividade política. Debutou na política como vereador em Porto Alegre em 1992. Em 1994 foi eleito pela primeira vez à Assembléia Legislativa. Por duas legislaturas atuou como presidente da Comissão de Saúde e Meio Ambiente da Assembléia Legislativa.

Debates do NER, Porto Alegre, ano 5, N. 6, P. 9-34, dezembro 2004 
bora se saiba que tenham circulado e procurado as diversas igrejas do campo evangélico.

Mas, ao longo da campanha não foram somente esses candidatos e essas coalizões que se aproximaram das igrejas e religiōes. Por exemplo, o Jornal Zero Hora, edição de 16 de agosto de 2004, publicou uma matéria intitulada "peregrinação em busca do voto de fiéis". Nela referia que o candidato a prefeito Beto Albuquerque, do PSB, compareceu no sábado, dia 14 do mesmo mês, a um culto celebrado no templo central da Igreja Adventista do Sétimo Dia, tendo prestado atenção durante uma hora e meia ao sermão do pastor. No dia seguinte, o candidato a prefeito pela Frente Popular, o deputado estadual Raul Pont, do PT, participou de uma celebração no templo da Igreja de Jesus Cristo dos Santos dos Últimos Dias, tendo ouvido durante duas horas a alternância de discursos e cânticos dos fiéis (Zero Hora, 16/8/2004).?

A Frente Popular, que além de Raul Pont como candidato a prefeito tinha a deputada federal Maria do Rosário como candidata a vice-prefeita, chegou a lançar um manifesto aos evangélicos, intitulado "Carta aos Evangélicos". Nela é lembrado que a Frente Popular "tem sido amiga das Igrejas Evangélicas, dando liberdade e incentivo ao culto religioso e às suas obras sociais"; e finaliza solicitando "a sua ajuda para que Porto Alegre continue crescendo e para que o Reino de Deus continue sendo propagado com a mesma liberdade e apoio que tem tido até agora”.

A RELigião na CAMPANHA PARA O Legislativo Municipal

Em Porto Alegre, nas eleições de 3 de outubro de 2004, 440 candida-

\footnotetext{
${ }^{7}$ Evidentemente que a procura política pelo voto religioso é um fenômeno bastante recorrente em todo o país. A propósito, a revista Veja, edição de 21 de julho de 2004, publicou uma repor tagem in titulada "O Evangelho segundo os políticos", on de discorre sobre os principais candidatos às prefeituras de São Paulo, Belo Horizonte e Rio de Janeiro e suas aproximações com igrejas e líderes religiosos na tentativa de obter seus apoios eleitorais.
}

Debates do NER, Porto Alegre, ano 5, N. 6, P. 9-34, DeZembro 2004 
tos concorreram às 36 cadeiras da Câmara Municipal. Entre eles, ao menos 21 possuíam vínculos religiosos explícitos, como veremos abaixo.

Como já escrevi em outro lugar (Oro, 2003c), para efeitos analíticos considero esses candidatos como sendo "religiosos políticos", uma vez que os seus vínculos religiosos são anterioresao seu ingresso na política e que tal ingresso ocorreu mediante o apoio, mais explícito para uns, menos explícito para outros, como veremos, dos fiéis das suas respectivas denominaçōes ou grupos religiosos. A expressão acima ainda pode ser mantida pelo fato de que após as eleições, os candidatos vitoriosos, no seu fazerpolítico continuama preservare, porvezes, a acionar os seus vínaulos identitários religiosos. Em oposição a essescandidatos, os demais poderiam ser denominados de "políticos laicos", não no sentido de serem semreligião, mas no de não colocarem em evidência seus pertencimentos e crenças religiosas, tanto na campanha política quanto em suas práticas políticas.

O quadro a seguir apresenta alguns dados informativos sobre os candidatos evangélicos nas eleições para a câmara municipal de Porto Alegre.

Quadro I - Evangélicos

\begin{tabular}{|c|c|c|c|c|c|}
\hline Denominaçáo & Nome & Função & Partido & Votos & Situaçáo \\
\hline Universal & $\begin{array}{c}\text { Valdir Caetano } \\
\text { da Silva }\end{array}$ & Pastor & PL & 10.138 & Eleito \\
\hline Universal & $\begin{array}{c}\text { Almerindo da } \\
\text { Rosa Filho }\end{array}$ & Pastor & PSL & 6.342 & Eleito \\
\hline $\begin{array}{c}\text { Total votos } \\
\text { da Universal }\end{array}$ & Eliseu Sabino & Pastor & PTB & 3.239 & Não-eleito \\
\hline $\begin{array}{c}\text { Assembléia } \\
\text { de Deus }\end{array}$ & Adão Macedo & Pastor & PDT & 373 & Não-eleito \\
\hline $\begin{array}{c}\text { Assembléia } \\
\text { de Deus }\end{array}$ & Paulo Eliseu & Evangelista & PSDB & 1.665 & Não-eleito \\
\hline $\begin{array}{c}\text { Assembléia } \\
\text { de Deus }\end{array}$ & Daniel Silva & Membro & PTB & 1.675 & Não-eleito \\
\hline $\begin{array}{c}\text { Assembléia } \\
\text { de Deus }\end{array}$ & & & 6.952 & \\
\hline $\begin{array}{c}\text { Total votos } \\
\text { da Ass. Deus }\end{array}$ & & & & & \\
\hline
\end{tabular}

(cont.)

Debates do NER, Porto Alegre, ano 5, N. 6, p. 9-34, dezembro 2004 
(cont.)

\begin{tabular}{|c|c|c|c|c|c|}
\hline Quadrangular & $\begin{array}{c}\text { Nilo Sergio } \\
\text { dos Santos }\end{array}$ & Pastor & PTB & 4.482 & Não-eleito \\
\hline $\begin{array}{c}\text { Total votos } \\
\text { Quadrangular }\end{array}$ & & & & 4.482 & \\
\hline Batista Filadélfia & $\begin{array}{c}\text { Cláudio } \\
\text { Conceição }\end{array}$ & Membro & PSDB & 3.588 & Não-eleito \\
\hline $\begin{array}{c}\text { Total votos } \\
\text { da Filadélfia }\end{array}$ & Elias Vidal & Membro & PTB & 5.541 & Eleito \\
\hline Adventista & Joáo Caetano & Membro & PSC & 254 & Não-eleito \\
\hline Adventista & Zeno de & Membro & PMN & 216 & Não-eleito \\
\hline Adventista & Oliveira & & & 6.101 & \\
\hline $\begin{array}{c}\text { Total votos } \\
\text { da Adventista }\end{array}$ & $\begin{array}{c}\text { Oscar } \\
\text { Lehenbauer }\end{array}$ & Pastor & PFL & 1.210 & Não-eleito \\
\hline $\begin{array}{c}\text { Luterana (IELB) } \\
\text { Total de votos } \\
\text { luteranos }\end{array}$ & & & & 1.210 & \\
\hline $\begin{array}{c}\text { Total de votos } \\
\text { evangélicos }\end{array}$ & & & & 38.723 & \\
\hline
\end{tabular}

O próximo quadro refere-se a dois candidatos católicos. ${ }^{8}$

\footnotetext{
${ }^{8}$ Não são os únicos católicos, eleitos para a Câmara Municipal de Porto Alegre, onde há mesmo um "Gru po de Verea dores Católicos", conforme será visto mais à frente no texto escrito por Antônio J. F. de Lima, Bruno Ribeiro Marques, Jonas de Souza Castilhos e Thais Vanessa. Estes estudantes discorreram sobre 4 vereadores que compõem o mencionado grupo, a saber: Ervino Besson, do PDT, eleito para a terceira legislatura com 6.459 votos; Beto Moesch, do PP, eleito para o segundo mandato com 11.215 votos; e Maria Celeste, do PT, também eleita para o segundo mandato, com 9.498 votos. Poderíamos ainda acrescentar os vereadores Carlos Garcia, do PSB, eleito com 5.848 votos, que será enfocado neste volume na análise feita por Mauro Meirelles e Aline Di Franco, e Aldacir Oliboni, também analisado neste volume por Daniel F. de Bem e Marcelo Tadvald.
}

Debates do NER, Porto Alegre, ano 5, N. 6, P. 9-34, Dezembro 2004 
Quadro II - Católicos

\begin{tabular}{|c|c|c|c|c|}
\hline Nome & Função & Partido & Votos & Situação \\
\hline João Carlos Nedel & Leigo & PPB & 6.787 & Eleito \\
\hline Aldacir Oliboni & Leigo & PT & 7.051 & Eleito \\
\hline Total & & & 13.838 & \\
\hline
\end{tabular}

O quadro abaixo contempla os candidatos pertencentes às religiōes afro-brasileiras.

Quadro III - Religiões Afro-Brasileiras

\begin{tabular}{|c|c|c|c|c|}
\hline Nome & Funçáo & Partido & Votos & Situação \\
\hline Jorge Verardi & Pai-de-Santo & PDT & 2.014 & Não-eleito \\
\hline Vera Soares & Mãe-de-Santo & PT & 623 & Não-eleita \\
\hline Angel Neto & Pai-de-Santo & PSB & 93 & Não-eleito \\
\hline Total & & & 2.730 & \\
\hline
\end{tabular}

O próximo quadro versa sobre o candidato espírita.

Quadro IV - Espiritismo

\begin{tabular}{|c|c|c|c|c|}
\hline Nome & Função & Partido & Votos & Situação \\
\hline André Luiz Irigon & Membro & PP & 616 & Não-eleito \\
\hline Total & & & 616 & \\
\hline
\end{tabular}

A seguir o quadro que se circunscreve ao Judaísmo

\begin{tabular}{|c|c|c|c|c|}
\hline Nome & Funçáo & Partido & Votos & Situação \\
\hline Isaac Ainhorn & Membro & PDT & 8.002 & Eleito \\
\hline Total & & & 8.002 & \\
\hline
\end{tabular}

Debates do NER, Porto Alegre, ano 5, N. 6, P. 9-34, Dezembro 2004 
Enfim, o quadro dos candidatos do que se pode chamar indivíduos religiosamente pertencentes ao movimen to "esotérico".

$$
\text { Quadro V- "Esotéricos" }
$$

\begin{tabular}{|c|c|c|c|c|}
\hline Nome & Funçáo & Partido & Votos & Situaçáo \\
\hline Carlos Assis Aymone & Agente religioso & PMDB & 585 & Não-eleito \\
\hline Maria da Graça Severo & Terapeuta holística & PFL & 220 & Não-eleita \\
\hline Total & & & 805 & \\
\hline
\end{tabular}

Total de votos dos candidatos religiosos -64.704

Uma primeira observação a ser feita sobre esses quadros é de que de um total de 36 cadeiras da Câmara Municipal, ao menos 6 delas serão ocupadas, a partir de 1 de janeiro de 2005, por vereadores para quem a identificaçáo religiosa não é secundária. São eles: 3 evangélicos (ValdirCaetano e Almerindo Rosa, da Universal, e Elias Vidal, da Adventista do Sétimo Dia), 2 católicos leigos (João Nedel e Aldacir Oliboni) e 1 judeu (Isaac Ainhorn).

Uma segunda observação é de que os 21 candidatos acima mencionados não publicizaram de forma igualitária os seus vínculos religiosos durante a campanha eleitoral.

Houve um primeiro grupo que o fez explicitamente, sobretudo durante os programas obrigatórios na rádio e na televisão. São eles: os pais-desanto Jorge Verardi - que comparecia no vídeo vestido com as indumentárias religiosas e conclamava os membros da sua religião a votarem em alguém da própria religião e não em "candidatos paraquedistas" - e Angel Neto, que se dizia Angel da Oxum, expressando assim a sua condição religiosa; os membros do grupo religioso alternativo, Assis Aymone, que na propaganda eleitoral gratuita na mídia se dizia praticante de Reiki e de outras práticas "eso", e Mariza da Graça Severo, que se dizia terapeuta holística; e os candidatos evangélicos Eliseu Sabino e Paulo Eliseu, que se proclamavam 
representantes oficiais da Assembléia de Deus, e Zeno de Oliveira, da Igreja Adventista, que se dizia "representante dos evangélicos".

Um segundo grupo não explicitou diretamente os seus vínculos religiosos e mesmo denominacionais, mas o discurso veiculado e os termos empregados denunciavam a sua pertença religiosa. Tal foi o caso dos candidatos evangélicosJoão Caetano,da Adventista do Sétimo Dia, que usava expressões tais como: "Porto Alegre com fê"; "Fé é a vitória"; "Vote com fé, meu irmão"; Valdir Caetano, da Universal, que mencionava já ser vereador e como tal havia proposto e viu aprovado um projeto de sua autoria que desobriga as igrejas e templos de pagamento do IPTU; e de Cláudio Conceição, da Igreja Batista Filadélfia, que repetia em seus pronunciamentos na mídia as expressões: "Porto Alegre é do Senhor Jesus" e "Tempo de fé para Porto Alegre".

Enfim, o tercei ro gru po não explicitou publicamente os seus pertencimentosreligiosos, embora o fizessem através de outras formas, como declaraçõesna imprensa,visitas a igrejas, templos, material gráfico produzido especialmente para os seus "irmãos de fé", etc. São eles: os católicos João Nedele AldacirOliboni, o espíritaAndré Luiz Irigon,o pastor Adão Leônidas Macedo, a mãe-de-santo Vera Soares, o pastor da Igreja Quadrangular Nilo Santos dos Santos, os evangélicos, Daniel Silva, da Assembléia de Deus e Elias Vidal, da Igreja Adventista, o pastor da Universal Almerindo Filho, o pastor luterano Oscar Lehenbauer e o judeu Isaac Ainhorn.

Neste último grupo, tudo indica que a não expressão pública dos vínculos religiosos obedece ao marketing político, ou seja, ponderaram ser prudente não acionar esse dispositivo por ocasião da campanha uma vez que alem de poder contar com os votos dos respectivos segmentos religiosos, já sabedores deste vínculo, poderiam, também, obter votos de muitos outros meios e segmentos sociais, que, eventualmente, poderiam se mostrar reticentes caso fosse veiculado publicamente as suas identidades religiosas.

\section{As estratégias de campanha dos candidatos religiosos}

Veremos agora como procederam os candidatos religiosos para moti- 
var os eleitores a votarem neles. Neste sentido, há uma diferença fundamental a ser feita entre os candidatos que compareceram como representantes "oficiais" de determinados segmentos religiosos, sendo, conseqüentemente, por eles apoiados, e aqueles que se apresentaram autonomamente como representantes ou membros de certas expressóes religiosas, sub-divididos, estes últimos, entre aquel es que obtiveram apoio semi-explícito das instituições religiosas às quais são filiados e aqueles que não contaram com nenhum apoio institucional. Na primeira categoria figuram alguns candidatos de igrejas evangélicas tais como a Universal do Reino de Deus, a Assembléia de Deus e a Quadrangular.

De fato, como já referi em outros lugares (Oro, 2003a; 2003b), desde 1977 a Igreja Universal adotou o modelo corporativo da "candidatura oficial" onde o número de candidatos depende do capital eleitoral de que dispóe em determinado município, ou estado. Para sabê-lo, efetua um levantamento do número de membros/fiéis/eleitores. Não ocorre nenhuma consulta prévia acerca da escolha dos possíveis candidatos junto aos membros das igrejas locais. Estes recebem, no momento oportuno, o(s) nome(s) em quem devem votar.?

Mas, a racionalidade política da IURD vai além disso. Ela distribui os seus candidatos segundo os bairros ou cidades, dependendo da eleição, para serem apoiados separadamente pelas diferentes igrejas locais. Dessa forma, ela pode saber antecipadamente o número aproximado de votos de cada candidato.

Em Porto Alegre, por ocasião das eleições 2004, a cúpula dirigente local da IURD optou por re-apresentar os mesmos pastores vereadores eleitos em 2000 como candidatos nas eleições de 2004. Como vimos, ambos foram reeleitos, especialmente, como veremos mais à frente, no texto escrito por Marcio Martins dos Santos e Graziele Ramos Schweig, devido ao fato de que, como nas vezes anteriores, toda a "máquina iurdiana" foi posta

\footnotetext{
9 Segundo P. Freston, duas são as características recorrentes aos candidatos da Universal, a de serem "pastores que atua m na mídia” (Freston, 2000:299).
}

Debates do NER, Porto Alegre, ano 5, N. 6, P. 9-34, DeZembro 2004 
em funcionamento, demonstrando, mais uma vez, nesta igreja, a força e o poder do carisma institucional (Oro, 2003a). ${ }^{10}$

Por sua vez, a Igreja Assembléia de Deus de Porto Alegre também reproduziu um modelo de fazer política já posto em prática nas eleições de 2000 e 2002. Ou seja, ela também ap resentou seus candidatos "oficiais", mas, em 2004, diferentemente das eleições anteriores, a escolha dos candidatos recaiu sobre os pastores e não sobre o grupo dirigente local da igreja. Com efeito, em junho de 2002, 120 pastores se reuniram e ouviram de quatro candidatos da igreja suas motivações e objetivos em se apresentarem como candidatos a uma cadeira na câmara municipal. Isto realizado os pastores procederam à eleição e escolheram os candidatos Eliseu Sabino e Paulo Eliseu, os quais passaram a ser apoiados "oficialmente" pela ig reja, tendo eles o direito de comparecerem nas igrejas para, nos finais dos cultos, fazerem uso da palavra. No entanto, como nas vezes anteriores, a cúpula dirigente local da Igreja não boicotou nem impediu a que outros membros-fiéis se apresentassem como candidatos. O resultado é que concorreram no mínimo 4 assembleianos em Porto Alegre e, como vimos, dividiram os votos entre si, não conseguindo eleger, novamente, nenhum deles.

Uma observação mais detalhada do que ocorreu nesta igreja, mas que, em grande medida, pode ser percebida também em outras igrejas que detém perfil semelhante a ela, revela que a não-eleição de nenhum candidato, malgrado seu potencial eleitoral capaz de eleger ao menos 1 vereador em Porto Alegre, deve-se ao fato de que não há unanimidade na Assembléia de Deus acerca da sua participação na política, tema este que será abordado por Valdir Pedde, neste mesmo volume. Ou seja, tanto junto aos pastores quanto aos seus membros há três diferentes tendências acerca desse tema.

\footnotetext{
${ }^{10}$ Recordo que L. Carneiro caracteriza a estrutura eclesial da IURD como sendo “carismática, centralizada e não participativa” (Carneiro, 1998). Esta estrutura, segundo este autor, faz desta igreja uma instituição onde "o carisma apresenta-se como o único elemento de organização do poder, da igreja local à organização nacional, constituindo u m espaço in stitucional pouco propício à participação dos fiéis nos ass untos da Igreja” (Carneiro, 1998:187).
} 
Há os que não concordam que a igreja participe diretamente na política, por exemplo, indicando e apoiando candidatos "oficiais"; há os que concordam com essa posição, mas não seguem a orientação de voto dado pela igreja; e há, enfim, aqueles que concordam com a escolha de candidatos oficiais e neles votam. Embora somente uma pesquisa mais aprofundada seja capaz de apontar as densidades de apoio de cada uma das três tendências constantes nessa tipologia, é possível que os fiéis-eleitores que se situam nas duas primeiras não votem nos candidatos oficiais da igreja, os primeiros porque se opõem à participação da igreja na política e os segundos porque não acatam a orientação de voto dos dirigentes. Diga-se de passagem que em razão disto alguns candidatos leigos se aproximam desta e de outras igrejas e religiōes para conquistar o voto dos fiéis descontentes com a participação das mesmas na política. Resta, então, o terceiro grupo da tipologia que vota nos candidatos oficiais da igreja. Mas, trata-se de uma parte (um terço?) dos fiéis da igreja. Parece-me que esta hipótese também precisa ser levada em conta na análise do fracasso de algumas igrejas evangélicas que apesar de indicarem e apoiarem seus candidatos oficiais não lograram êxito nas últimas campanhas eleitorais em Porto Alegre e alhures.

Enfim, a Igreja do Evangelho Quadrangular reproduz em parte o que fazem as igrejas Universal e Assembléia de Deus. Tal como elas, procede à indicação de candidato(s) oficial(is) da igreja. De forma semelhante à Universal procede a um levantamento prévio do capital político de que dispõe e, da mesma forma como a Assembléia, a escolha do(s) representante(s) ocorre mediante uma votação secreta realizada pelos pastores, em Porto Alegre, em torno de 50. Foi com base nestes procedimentos que o mesmo pastor, Nilo Sergio dos Santos, apoiado nas eleiçôes de 2000 foi novamente indicado e apoiado para concorrer à câmara municipal nas eleições de 2004, não logrando se eleger, mas tendo ficado na segunda suplência do PTB.

Relativamente aos candidatos religiosos que se apresentaram autonomamente como representantes ou como membros de certos segmentos religiososcabe uma distinçãoentre aqueles que, apesar de autônomos, lograram obter, de alguma forma, algum apoio institucional e aqueles que não contaram com nenhum apoio institucional. 
$\mathrm{Na}$ primeira categoria figuram alguns candidatos evangélicos como Cláudio Conceição, da Igreja Batista Filadélfia, Elias Vidal, da Igreja Adventista, e Oscar Lehenbauer, da igreja Luterana, assim como o candidato do grupo judaico e os candidatos católicos. Nenhum deles parece ter sido indicado oficialmente pelas suas respectivas religiões e igrejas, mas delas tiveram alguma forma de apoio, em termos, por exemplo, de mediação e facilitação institucional no contato com eleitores-fiéis, especialmente em dias de concentração popular para realização de rituais.

Neste sentido, vale recordar que a Igreja Católica, enquanto instituição, reproduziu nas últimas eleições, a nível local, regional e nacional, o comportam ento que vem adotando há vários anos. Ou seja, ao menos a posição oficial foi de não disputar cargos políticos e de não indicar e apoiar nenhum candidato, seja ele laico ou membro do clero. Porém, como nas demais eleições, também nesta última as autoridades eclesiásticas se manifestaram no sentido de orientar o voto dos fiéis. Assim, em texto publicado na Folha de São Paulo, no dia das eleições municipais, Dom Geraldo Majella Agnello, presidente da CNBB, chamou a atenção dos fiéis, da seguinte forma:

"Estimulamos que a escolha do candidato se faça a partir do seu programa, do respeito ao pluralismo cultural e religioso, do comportamento ético, do compromisso com a justiça e a partir de qualidades como honestidade, competência, liderança, transparência, vontade de servir ao bem comum. Conheça a história de vida do candidato para que seu voto comece a mudar sua pró pria história de vida!" (Folha de São Paulo, 3/10/2004).

Já o arcebispo metropolitano de Porto Alegre, dom Dadeus Grings, divulgou, em julho de 2004, a cartilha "Política - Eleiçôes Municipais 2004", cujo lançamento ocorreu na reuniāo-almoço da Associação de Dirigentes Cristãos de Empresas (ADCE), na Igreja da Pompéia. Composta de 44 páginas e 12 capítulos, a cartilha diz, entre outras coisas, o seguinte:

"Temos (...) critérios para votar em alguém. E, no plano municipal, onde as pessoas mais facilmente se conhecem, eles são mais fáceis de serem entendidos 
e aplicados. (...) No plano ideológico, para nós o critério fundamental é a valorização da vida. Nos primeiros tempos do cristianismo, três pecados, considerados os mais graves, exigiam penitência pública: o homicídio, o adultério e a apostasia".

E mais à frente afirma: "Muitos candidatos, apesar de todas as leis em contrário, continuam servindo-se das carências do povo para conseguir votos. Com isto ficamos apenas numa pretensa democracia". ${ }^{11}$

Por sua vez, a Igreja Evangélica de Confissão Luterana no Brasil lançou pela primeira vez uma carta pastoral sobre as eleições de 2004. Nela, diz o seu pastor-presidente, Walter Altmann,

"não queremos o uso do voto para fins pessoais. A carta orienta os fiéis a fazerem uso das eleições para promover o bem comum. Queremos que os luteranos sejam agentes políticos ativos sempre" (Zero Hora, 13/8/2004).

Continuando com a análise da segunda categoria dos candidatos que se apresentaram autonomamente como representantes ou membros de certos segmentos religiosos, destaca-se aqueles que assim procederam, mas não obtiveram apoio institucional. Tal parece ter sido o caso do candidato que se dizia "represen tante dos evangélicos", Zeno de Oliveira, dos 3 candidatos das religiōes afro-brasileiras, ${ }^{12}$ do candidato espírita e dos 2 candidatos do que denominamos representantes do campo "esotérico", ou da "Nova Era", os quais efetuaram a sua campanha baseada fundamentalmente nos esforços pessoais, não obtendo, ou obtendo precariamente, facilitações de parte, por

\footnotetext{
${ }^{11}$ Em texto mais à frente Antônio J. F. de Lima, Bruno Ribeiro Marques, Jonas de Souza Castilhos e Thais Vanessa Salvador, irão analisar 4 candidatos católicos, re-eleitos à Câmara municipal, e que integram o Grupo de Vereadores Católicos de Porto Alegre. Por sua vez, Daniel F. de Bem e Marcelo Tadvald, em outro texto, abordarão as interaçóes político-religiosas presentes no discurso e na prática discursiva de outro candidato católico re-eleito à Câmara municipal, Aldacir Oliboni.

${ }^{12}$ Estes serão analisados detalhadamente, mais à frente, em texto escrito por Andréa Grazziani Otero, Cíntia Aguiar de Ávila e Rosilene dos Santos Schoenfelder.
} 
exemplo, das Federaçōes de Religiões Afro-Brasileiras, no caso dos pais-desanto, da Federação Espírita, no caso do candidato oriundo deste segmento religioso, e dos centros esotéricos, no caso dos 2 candidatos da Nova Era. ${ }^{13}$

Evidentemente que o pouco, parco, ou nenhum apoio institucional contribuiu para o resultado negativo dos candidatos acima mencionados, exceto os católicos, para quem a identificação católica consiste num, entre muitos outros, potenciais apelos motivadores de seus votos, conforme será visto mais à frente em textos deste volume.

\section{ANÁLISE COMPARATIVA DAS ELEIÇÕES 2000 E 2004 EM PORTO ALEGRE}

Várias observações podem ser feitas em relação à aproximação dos campos religioso e político ocorrida entre as eleiçōes de 2000 e de 2004, em Porto Alegre.

Uma primeira consiste em perceber que nas últimas eleiçōes houve não somente um aumento em relação a 2000 do número de candidatos que se proclamaramreligiososou representantes de expressõesreligiosas, mas também que tal aumento significou uma ampliação da presença de representantes das expressões religiosas que compõem o pluralismo religioso local.Assim, além de candidatos representantes do catolicismo, das igrejas evangelicas históricas e pentecostais, das religióes afro-brasileiras e do judaísmo, que apareceram no ano 2000, em 2004 encontramos candidatos que afirmaram publicamente a sua condição espírita e da "Nova Era". Assim, embora distribuídos de forma desigual em relação ao universo de fiéisque compõem a diversidadereligiosade Porto Alegre, ao menos as principais religiōes, tiveram, de alguma forma, algum seu representante como candidato nas eleiçōes de 2004.

Vale a pena recordar, olhando a tabela abaixo, montada a partir dos

${ }^{13}$ O principal candidato, representante deste segmento religioso, será objeto de um capítulo neste volume, escrito por Nicolas Guigou e Suzana Araujo.

Debates do NER, Porto Alegre, ano 5, N. 6, p. 9-34, dezembro 2004 
últimos Censos de 1991 e de 2000, como se apresenta a diversidade religiosa no Rio Grande do Sul, comparada com a brasileira. ${ }^{14}$

Dados comparativos dos Censos de 1991 e 2000 - RS e Brasil

\begin{tabular}{|c|c|c|c|c|c|c|}
\hline \multirow{2}{*}{ Religião } & \multicolumn{2}{|c|}{ Brasil } & & \multicolumn{2}{c|}{ R. S. } & \\
\cline { 2 - 7 } & 1991 & 2000 & Variação (\%) & 1991 & 2000 & Variação (\%) \\
\hline Católica & 82,9 & 73,6 & $-11,2$ & 81,3 & 76,6 & $-4,7$ \\
\hline Evangélicas & 8,5 & 15,4 & +80 & 10,8 & 13 & $+20,4$ \\
\hline Espírita & 1,1 & 1,3 & $+23,2$ & 1,4 & 2,1 & $+44,5$ \\
\hline Umbanda/Candomblé & 0,4 & 0,3 & $-22,7$ & 1,2 & 1,6 & $+33,6$ \\
\hline Judaica & 0,06 & 0,06 & 0 & 0,09 & 0,1 & $+11,1$ \\
\hline Orientais & 0,25 & 0,25 & 0 & 0,05 & 0,07 & +40 \\
\hline Outras & 0,06 & 1,2 & +1.983 & 0,07 & 1,6 & +2.314 \\
\hline Sem religião & 4,7 & 7,2 & $+53,4$ & 2,9 & 4,3 & $+50,4$ \\
\hline Não determinada & 0,4 & 0,2 & $-43,9$ & 0,2 & 0,19 & $-9,52$ \\
\hline
\end{tabular}

Como se pode ver, se, por um lado, as percentagens de candidatos não correspondem exatamente ao montante das representaçôes religiosas existentes no estado, por outro lado, quase todas as expressóes religiosas acima arroladas (catolicismo, evangélicos - histórico e pentecostal - religiōes afrobrasileiras, espiritismo, judaísmo, religiōes orientais e "outras", e, certamente, os sem religião) tiveram ao menos um seu representante concorrendo como candidato a uma vaga na câmara municipal de Porto Alegre.

Portanto, nas eleições 2004 em Porto Alegre constatamos um aumento de representaçáo política da diversidade religiosa, tendo logrado êxito, porém, representantes não necessariamente das maiores representaçóes religiosas, mas antes daquelas que melhor se organizaram e se mobilizaram para eleger os seus candidatos. Foram elas a Igreja Universal, a Igreja Adventista e

${ }^{14} \mathrm{O}$ objetivo do quadro que segue não é proceder a uma análise do mesmo em perspectiva quantitativa e comparativa. Também não se trata de discorrer sobre o tamanho da diversidade religiosa existente em nosso país, como faz, por exemplo, Antônio Flavio Pierucci (1997). Pretendo, tão somente, mostrar a diversidade religiosa existente no Brasil em geral, e no Rio Grande do Sul, em particular.

Debates do NER, Porto Alegre, ano 5, N. 6, P. 9-34, DeZembro 2004 
o Judaísmo, e com êxito parcialas igrejasQuadrangulare Assembléia de Deus. A eleição de candidatos que se dizem católicos ainda merece um aprofundamento para melhor perceber em que medida a variável religiosa incidiu de fato sobre as suas eleições, sabendo que se trata de candidatos, como já disse, que cativam votos de um amplo universo social, onde a variável religiosa consiste num elemento, entre outros, de apelo eleitoral.

Uma segunda observação conceme à recorrência de candidatos religiosos não somente para o legislativo, mas também para o executivo municipal. De fato, nas eleições 2000,como vimos, a União Trabalhista apresentouo candidato a prefeito, Alceu Collares, e a vice-prefeita, Sonia Santos, como políticos de declarada inserçáo religiosa,o primeiro no campoafro-brasileiroe a segunda no evangelico. Nas eleiçôes 2004, vimos se repetir a presença religiosa em chapa que disputou e venceu a eleição para a prefeitura municipal. Trata-se do viceprefeito eleito, Eliseu Santos, ex-marido de Sonia Santos, um deputado que assumepublicamente seusvínculos com a religião evangêlicapentecostal. Além disso, como já disse, nas últimas eleições houve outro candidato a prefeito representante do segmento evangélico, o luterano Onyx Lorenzoni.

Mas, comparando os dados das eleiçôes 2000 e de 2004, nota-se, ainda, e agora relativamente aos candidatos ao legislativo municipal, a recorrência não somente de representantes dos mesmos segmentos religiosos em ambos os pleitos, mas também dos mesmos indivíduos que se apresentaram nas duas oportunidades. Neste sentido, a primeira distinção a ser feita é entre aqueles que foram eleitos em 2000 e lograram manter o seu mandato em 2004. A tabela abaixo mostra essa recorrência.

Candidatos religiosos eleitos em 2000 e em 2004

\begin{tabular}{|c|c|c|c|c|}
\hline Nome & Religião & Partido & Votos (2000) & Votos (2004) \\
\hline Valdir Caetano & Universal & PTB & 10.913 & 10.138 \\
\hline Almerindo Filho & Universal & PFL & 7.645 & 6.342 \\
\hline Elias Vidal & Adventista & PTB & 5.116 & 5.541 \\
\hline Joáo Carlos Nedel & Católica & PPB & 6.039 & 6.787 \\
\hline Aldacir Oliboni & Católica & PT & 5.188 & 7.051 \\
\hline Isaac Aynhorn & Judaica & PDT & 10.830 & 8.002 \\
\hline
\end{tabular}

Debates do NER, Porto Alegre, ano 5, N. 6, P. 9-34, Dezembro 2004 
Como se vê, os 6 vereadores religiosos que se reapresentaram como candidatos nas eleições 2004 conseguiram se reeleger. Isto mostra, como se sabe, que o político detentor de um mandato, seja ele em que nível político for, possui alguma vantagem em relação àqueles que disputam uma vaga em alguma instituição política cujo ingresso ocorre mediante o voto.

Chama atenção, também, que de uma eleição para outra, 3 vereadores reduziram o número de votos e 3 outros aumentaram. A redução maior, na ordem de quase 3 mil votos, ocorreu com o candidato vinculado ao judaísmo. É surpreendente, também, que os dois vereadores da Universal tiveram uma redução de votos, embora pequena, de uma eleição para outra, mesmo sabendo que nos últimos quatro anos a Universal, como igreja, continuou a crescer e, como vimos, especificam ente no que tange à prática política, a igreja continuou a proceder segundo o marketing posto em prática nas eleições $2000 .{ }^{15}$ Enfim, 3 candidatos aumentaram a sua votação. Foram eles, os candidatos católicos Oliboni, Nedel e o adventista Elias Vidal.

A próxima tabela mostra os candidatos que se apresentaram nas eleições 2000 e nas eleições 2004 não sendo eleitos em nenhum dos pleitos.

${ }^{15}$ Como Marcio Martins dos Santos e Graziele Ramos Schweig irão mostrar em texto escrito neste volume, a redução dos votos dos vereadores em Porto Alegre constitui um dos sinais de um fenômeno mais amplo envolvendo a Universal, ocorrido nestas eleições, em que a redução de votos se traduziu numa importante redução de eleitos, pois se no país como um todo a Universal conseguiu eleger nas últimas eleições 70 vereadores, nas eleiçôes do ano 2000 este número havia chegado a 360 vereadores (Jornal O Globo, edição de 17/10/2004). Este fato ainda espera uma análise por parte dos estudiosos no tema. Coincidência ou não, este relativo fracasso da Universal nas eleições 2004 ocorreu quando Carlos Rodrigues não atuou como coordenador e organizador político da igreja, ele que, como já disse, foi deposto deste cargo e perdeu o título de bispo. No entanto, sabendo que até as últimas eleições era ele o estrategista e homem forte da Universal no que tange às questôes políticas, é possível levantar a hipótese de que sua ausência tenha deixado uma lacuna na igreja, ainda não preenchida, cujo resultado foi o relativo fracasso nas eleições 2004.

Debates do NER, Porto Alegre, ano 5, N. 6, P. 9-34, DeZembro 2004 
Candidatos religiosos não-eleitos em 2000 e em 2004

\begin{tabular}{|c|c|c|c|c|}
\hline Nome & Religião & Partido & Votos (2000) & Votos (2004) \\
\hline Eliseu Sabino & Assembléia de Deus & PTB & 3.665 & 3.239 \\
\hline Paulo Eliseu & Assembléia de Deus & PSDB & 1.714 & 1.665 \\
\hline Nilo dos Santos & Quadrangular & PTB & 2.333 & 4.482 \\
\hline Cláudio Conceição & Batista Fidalélfia & PSDB & 1.949 & 3.588 \\
\hline João Caetano & Adventista & PSC & 344 & 254 \\
\hline Jorge Verardi & Afro-brasileira & PDT & 1.994 & 2.014 \\
\hline
\end{tabular}

Relativamente aos 6 candidatos que concorreram nos dois pleitos à câmara municipal de Porto Alegre, nota-se que 3 deles tiveram uma redução no número de votos de uma eleição para outra. São eles os 2 candidatos da Assembléia de Deus e o candidato da Igreja Adventista, pelas razões já apontadas acima. Já os 3 outros candidatos aumentaram o número de votos, sendo queo aumento menorocorreucom o pai-de-santo da religiãoafro-brasileira, e o aumento mais significativo deu-se com o candidato da Igreja Batista Filadélfia, que quase duplicou o número de votos, o mesmo ocorrendo com o candidato da Igreja Quadrangular. Isto mostra, certamente, o engajamento político efetuado pelas instituiçõesreligiosas em questão.E tal esforço produziu resultado pois o can didato representan te "oficial" da Quadrangular figura hoje como o segundo suplente de vereador do PTB, enquanto que o candidato da Igreja Batista Filadélfia é o terceiro suplente do seu partido, o PSDB. Já o representante das religiões afro-brasileiras entrou como 12 suplente.

Portanto, 12, entre os 21 candidatos a vereador pela câmara municipal de Porto Alegre, já haviam participado como candidatos nas eleiçōes 2000, 6 deles tendo sido eleitos, e agora re-eleitos, e os outros 6 derrotados nas duas oportunidades. Os 9 demais candidatos nas eleiçôes 2004 fizeram sua estréia na política municipal.

\section{CONCLUSÃO}

A procura pelas religiões e igrejas por parte dos políticos, especialmente por ocasião do "tem po da política" (Palmei ra, 2002), faz par te da cultura 
política brasileira, da mesma forma como, com menor incidência, mas com tendência crescente, presenciamos a inserção de instituições religiosas e de religiosos na política. Mas este não é um fenômeno somente local, regional e nacional. Ele é também internacional, onde "política e religião não podem (mais) se ignorar" (Bauer, 1999, p. 86). Este fato está associado, segundo alguns analistas do macro-contexto, no dizer de Geertz (2001), à desilusão em relação às grandes ideologias e ao fracasso das promessas da modernidade, e, especificamente em relação ao campo político, a um "déficit global" do político, ou seja, a um certo "desencantamento" do político que vigora nos dias atuais no ocidente (Michel, 1997). Também em relação ao Brasil este fenômeno ocorre, sobretudo o último, posto que, segundo Renato Janine Ribeiro, aqui a imagem dos políticos é ruim, "a opinião pública brasileira é bastante cética em relação aos políticos” (Ribeiro, 2002:99), já que sua prática está, em certa medida, associada ao patrimonialismo, ao nepotismo e à corrupção. Esta afirmação de Ribeiro é comprovada por uma pesquisa realizada pelo instituto Gallup, divulgada em novembro deste ano de 2004, sobre o grau de confiança em relação aos políticos em diversos países do mundo. O Brasil é o país que detém a mais alta cifra de desconfiança em relação aos políticos. São $90 \%$ dos brasileiros que afirmaram não confiar nos políticos, enquanto que a média dos países europeus é de 50\% (Zero Hora, 17/11/2004).

Neste caso, vale sublinhar, em primeiro lugar em relação ao Brasil, que a aproximação entre o político e o religioso não consiste numa tentativa "fun damentalista" de instauração de uma hegemonia ideológica exclusivista, semelhante ao que ocorre em outros contextos, com outras religióes. ${ }^{16}$ Tam-

\footnotetext{
${ }^{16}$ Tal é o caso, por exemplo, do fundamentalismo islâmico que, segundo David Martin, procura instaurar, em diversos países, uma hegemonia ideológica e submeter todos os cidadãos às prescrições da lei islâmica. No caso dos evangélicos na política latino-americana, ao contrário disso, "a ambição (...) é somente, com uma ou duas exceçôes, constituir um grupo de pressão eficaz para defender seus interesses institucionais e os princípios morais em seu sentido amplo, e de fazer ouvir suas vozes no debate público" (Martin, 2001:63-64).
}

Debates do NER, Porto Alegre, ano 5, N. 6, P. 9-34, DeZembro 2004 
bém, embora este seja um tema controvertido, não parece ser o caso de se ver em tal ap roximação um "retrocesso" da democracia republicana. ${ }^{17} \mathrm{E}$, enfim, também não se trata de se abordar tal aproximação como sendo a expressão de insuficiência de consciência política. ${ }^{18}$ Antes, parece ser heuristicamente mais pertinente se ver, neste processo, um "recurso cultural" detentor de efeitos políticos, ${ }^{19}$ levado a efeito por uma sociedade em que "o domínio do "sobrenatural" aparece como fundamental para compreender o sistema de rep resentações..." (Velho, 1991:129), onde se observa "uma luta para ampliar a dimensão religiosa do espaço público e não por laicizá-lo" (Carvalho, 1999, p. 16), e onde, "o plano material e o sobrenatural são muitas vezes muito próximos" (Capone, 1999, p. 34). Esta autora acrescenta que "em nenhum outro país do mundo não se verá tratado com tanta naturalidade o tema da mediunidade (...). No Brasil, os espíritos habitam os homens e habitam com os homens" (Id. Ibid.).

A abrangência geográfica do fenômeno conduz também, em segundo lugar, a que se perceba, mais amplamente, em diversos sistemas culturais atuais, uma relação entre religião e política que parece ser menos de oposição e mais de passagens entre elas (Novaes, 2002), ou de deslocamento de fronteiras (Burity, 2000), que vem questionar os limites erguidos entre o político e o religioso e, por via de conseqüência, a pertinência do conceito

\footnotetext{
${ }^{17}$ Recordo, neste particular, com Dodson, que há diferentes tendências entre os autores que analisam, por exemplo, a presença evangélica na política. Alguns tem enfatizado as conseqüências sociais de tal presença; outros tem sublinhado os efeitos políticos, particularmente no estímulo aos valores e práticas democráticas; enfim, outros são céticos quanto à possibilidade de relação mútua benéfica entre religião e política (Dodson, 1997:25-26).

${ }^{18}$ Aplica-se aqui a advertência de Geertz. Para ele, "a visão que parece subjazer a inúmeras análises da expressão religiosa (...) de que a religião não passa de uma máscara e uma mistificação, um encobrimento ideológico de ambiçōes perfeitamente seculares e mais ou menos egoístas, simplesmente não é plausível” (Geertz, 2001, p. 59).

${ }^{19}$ Referindo-se especificamente à bíblia, mas poderíamos estender para a religião em geral, R. Novaes chama a atenção para o fato de que "na era da informação, em pleno século XXI, a Bíblia continua sendo um poderoso "recurso cultural" para a compreensão do mundo e para a ncorar escolhas religiosas com efeitos políticos” (Novaes, 2001, p. 80).
} 
de secularização e de desencantamento do mundo, não somente em relação à sociedade brasileira, mas também à sociedade ocidental como um todo, como expôs recentemente Peter Berger (2001).

Enfim, vale frisar que além das análises teóricas sobre as "relações delicadas en tre religião e política”, como bem lembra Regina Novaes (2001), faz-se necessário também avançar nos estudos etnográficos - embora eles estejam acontecendo pelo Brasil afora - sobre a atuação parlamentar dos religiosos políticos, seja a nível municipal, estadual ou federal, para saber se conseguem, de alguma forma, e em que direção, incidir sobre o político, ou, se, ao contrário, são tragados pela força vampirizadora do político, "este cemitério do que há de melhor na sociedade”, na forte expressão de Renato Janine Ribeiro (2002, 104-105).

\section{REFERÊNCIAS}

BAUER, Julien. Politique et Religion. Paris,PUF,1999 (coleção Que sais-je?).

BERGER, Peter. La désécularisation du monde: un point de vue global. In: BERGER, Peter (Org.). Le réenchantement du monde. Paris, Bayard, 2001, p. 13-36.

BURITY, Joanildo.Identidade e Políticano Campo Religioso. Recife, IPESPE, Editora Universitária/UFPE, 1997.

BURITY, Joanildo. Religiāo e Politica na Fronteira: desinstitucionalização e deslocamento numa relação historicamente polêmica. Paper apresentado no VIII Congresso Latino-americano de Religião e Etnicidade, promovido pela Associação Latino-americana para o Estudo das Religiōes, em Pádua, Itália, de 27/06 a 05/07/2000.

CARNEIRO, Leandro Piquet.(1998) "CulturaCívica e Partiaipação Política entre Evangélicos”. In: FERNANDES et alii. NovoNascimento. Os evangélicos em casa, na Igreja e na Política. Rio de Janeiro, Mauad, p. 81-210. 
CARVALHO, José Jorge de. Um espaço público encantado. Pluralidade religiosa e modernidade no Brasil. Brasília, Universidade de Brasília, Série Antropologia, n. 249, 1999.

DEBATES DO NER, Religião e eleições 2000 em Porto Alegre. Porto Alegre, UFRGS, ano 2, n. 3, 2001.

CAPONE, Stefania. La quête de l'Afrique dans le Candomblé. Pouvoir et tradition au Brasil. Paris, Karthala, 1999.

DODSON, Michael.Pentecostals, Politics, and Public Space in LatinAmerica. In: ClEARY, E.; STEWART-GAMBINO, H, (Org). Power, Politics and Pentecostals in Latin America. Boulder, Westview Press, 1997, p. 25-40.

FRESTON,Paul. The Polítical Evolutionof Brazilian Pentecostalism: 19862000. In: CORTEN, Andre; MARY, Andre (Org). Imaginaires Politiques et Pentecôtisme: Afrique et Amérique. Paris, Ed. Karthala, 2000, p. 287-306.

GEERTZ, Clifford. Nova luz sobre a Antropologia. Rio de Janeiro, Jorge Zahar Editor, 2001.

JORNAL FOLHADE SÃO PAULO, ediçōes de 20/02/2004e de 3/10/2004. JORNAL O GLOBO, edição de 17/10/2004.

JORNAL ZERO HORA, edições de 13/8/2004, 16/8/2004 e 17/11/2004.

MARTIN, David.La pousséeévangélisteet ses effetspolitiques.In: BERGER, Peter (Org.). Le réenchantement du monde. Paris, Bayard, 2001, p. 61-78.

MICHEL, Patrick. Introduction. In: MICHEL, Patrick (Org). Religion et Démocratie. Paris, Albin Michel, 1997, p. 9-28.

NOVAES, Regina. A divina política. Notas sobre as relações delicadas entre religiãoe política. RevistaUSP, São Paulo, n. 40, março/maio2001, p. 60-81. ORO, Ari Pedro. A política da Igreja Universal e seus reflexos nos campos religioso e político brasileiros. Revista Brasileira de Ciências Sociais, v. 18, n. 53, outubro de 2003a, p. 53-70. 
ORO, Ari Pedro. Organização eclesial e eficácia política: o caso da Igreja Universal do Reino de Deus. Civitas, Porto Alegre, PUC/RS, v. 3, n. 1, junho de 2003b, p. 97-110.

ORO, Ari Pedro. Principes religieux et pratiques politiques des "religieux politiciens" et des "politiciens laiques" au Sud du Brésil. Trabalho apresentadona 27a Réunion Internationale de Sociologiedes Religions, Turim, Itália,2003c.

PALMEIRA, Moacir. Política e tempo: nota exploratória. In: PEIRANO, Mariza (Org). O dito e o feito: ensaios de antropologia dos rituais. Rio de Janeiro, Relume Dumará, 2002, p. 171-177.

PIERUCCI, Antônio Flávio. Interesses religiosos dos sociólogos da religião. In: ORO, Ari Pedro; STEIL, Carlos Alberto. Globalização e Religiāo. Petrópolis, Vozes, 1997, p. 249-262.

REVISTA VEJA, edição de 21 de julho de 2004.

RIBEIRO, Renato Janine. Religião e política no Brasil contemporâneo. In: FRIDMAN, Luis Carlos (Org). Politica e Cultura. Século XXI. Rio de Janeiro, ALERJ, Relume Dumará, 2002, p. 99-110.

SANCHIS, Pierre. Desencanto e formas contemporâneas do religioso.

Ciencias Sociales y Religión, Porto Alegre, ano 3, n. 3, 2001, p. 27-43.

VELHO, Gilberto. Indivíduo e religião na cultura brasileira. Novos Estudos - CEBRAP. n. 31, outubro de 1991, p. 121-129. 